\title{
SUBTOTAL THYROIDECTOMY; COMPARING THE MEAN OPERATIVE TIME WITH HARMONIC SCALPEL VERSUS CONVENTIONAL VESSEL LIGATION METHOD
}

1. MBBS, FCPS

Assistant Professor of Surgery Bakhtawar Amin Medical and Dental College Multan.

2. MBBS, FRCS

Associate Professor of Surgery Bakhtawar Amin Medical and Dental College Multan.

3. MBBS.

House Officer

Ibn e Sina Hospital Multan

4. MBBS, FCPS

Assistant Professor

Nishtar Institute of Dentistry

Multan.

Correspondence Address:

Dr. Aamir Furqan

Assistant Professor

Nishtar Institute of Dentistry

Multan.

draamir2009@hotmail.com

Article received on:

05/06/2017

Accepted for publication:

$15 / 08 / 2017$

Received after proof reading: 06/10/2017

\begin{abstract}
Shabbir Ahmed 1 , Ishtiaq Ahmad ${ }^{2}$, Asad Riaz ${ }^{3}$, Aamir Furqan ${ }^{4}$
ABSTRACT... Objectives: To compare the mean operative time in subtotal thyroidectomy with harmonic scalpel and conventional vessel ligation method. Study Design: Randomized control trial. Setting: Surgical unit of Bakhtawar Amin Medical and Dental College Multan. Period: April 2015 to April 2016 for one year. Methodology: A total number of 92 cases were selected for this study and these were randomly divided into two equal groups by lottery method (Group $A=$ operated with harmonic scalpel, Group $B=$ operated with conventional vessel ligation method) each containing 46 patients. The sample size was calculated with the help of the WHO Sample Size Calculator. (WHO sample size determination software version of KC Lun and Peter Chiam). Sample Size, $n=92$ (46 in each group). Expected mean operative time with harmonic scalpel method $(44.9 \pm 8.3$ minutes) compared with the Conventional ligation method $(69.5 \pm$ 10.7 minutes; $P<.001$ ). Data was analyzed with the use of SPSS version 23 . The frequency and percentage were calculated for qualitative variables like gender. Quantitative variables like age and operative time were presented as mean and standard deviation. T test was applied to compare the mean operative time between two groups. Results: A total number of $100 \%$ $(n=92)$ patients were included in this study. Gender distribution showed that there were more males i.e $52.2 \%(n=48)$ and $47.8 \%(n=44)$ were females. The mean age of patients was 42.75 +14.33 years. Recorded mean duration of operation time was $47.69+6.51$ minutes for group A compared to the mean duration of operation of $71.61+7.32$ minutes. This time difference was statistically significant with a p-value of $<0.001$. Conclusion: Subtotal thyroidectomy with harmonic scalpel leads to a significantly reduced mean operative time compared to conventional vessel ligation technique and should be opted routinely for this surgical procedure.
\end{abstract}

Keywords: Harmonic Scalpel, Mean Operative Time, Conventional Vessel Ligation Technique, Subtotal Thyriodectomy.

Article Citation: Ahmed S, Ahmad I, Riaz A, Furqan A. Subtotal thyroidectomy; comparing the mean operative time with harmonic scalpel versus conventional vessel ligation method. Professional Med J 2017;24(10):1544-1549.

DOI:10.17957/TPMJ/17.4030

\section{INTRODUCTION}

Multinodular goiter (MNG) is a commonly encountered problem of thyroid gland in our area. Cosmetic problem is the most common presentation of a patient coming to OPD with multinodular goiter. Other presentation of MNG includes problems like respiratory difficulty ${ }^{1}$, thyrotoxicosis, dysphagia ${ }^{2}$ and malignancy in long standing cases of this disease..$^{3,4}$ Total thyroidectomy is the most common procedure performed for MNG in the developed countries. Poor compliance, neglected follow up system and shortage of life saving drugs including thyroxin go in favour of subtotal thyroidectomy (STT) in the developing countries like Pakistan.
Surgical approach deviced by Kocher, more than a century ago, is still used today with only slight alteration. ${ }^{5}$ Relatively small operative field and profound vascularity of the thyroid gland highlights the importance of the meticulous hemostasis for a successful outcome in thyroid surgery. Conventional vessel ligation method including clipping and/or tying of blood vessels ${ }^{6}$ is a time-consuming process. Competent surgeons are in search of time saving surgical methods with minimum complication rates in order to meet the demand of ever increasing surgical list.

Use of Harmonic Scalpel, for surgical procedures, 
was intiated about a decade ago. ${ }^{7}$ This device uses mechanical vibrations of $55.5 \mathrm{kHz}$ for simultaneous cutting and coagulation of the tissue. ${ }^{8}$ Lack of neuromuscular stimulation, minimum lateral thermal energy damage ${ }^{9}$, reduced smoke production and avoidance of direct electrical energy passage through the body are the various factors that give an upper hand to the use of harmonic scalpel over the traditional electro cautery. Diminished blood loss was reported in a randomized prospective clinical trial with the use of harmonic scalpel in the modern surgical practice. ${ }^{10}$

Within the last decade, the evaluation of the utilization of the Harmonic Scalpel in thyroid surgery was done at various European centers. Reduction of mean operating time was significant on utilizing focus $\mathrm{HS}$ compared to that of Conventional vessel ligation method in total Thyroidectomy. ${ }^{11}$ Use of conventional ligation took longer (69.5 \pm 10.7 minutes) than that of harmonic scalpel (44.9 \pm 8.3 minutes) with the $p$ value of $<.001$, making it a significant time saving method of open total thyriodectomy in a prospective randomized trial. ${ }^{12}$ Moreover, a nearly 25 percent of the total operating room time was reduce with the use of HS in another study..$^{13}$ Higher level of efficacy and safety of utilizing harmonic scalpel was not threatened by any increase of complication rate. ${ }^{14}$

\section{METHODOLOGY}

In total 92 cases were taken for subtotal thyroidectomy and these were randomly divided into two equal groups (Group $A=$ operated with harmonic scalpel, Group $\mathrm{B}=$ operated with conventional vessel ligation method) each containing 46 patients. Sample Size, $n=92$ (46 in each group). Expected mean operative time with harmonic scalpel method (44.9 \pm 8.3 minutes) compared with the Conventional ligation method $(69.5 \pm 10.7$ minutes; $P<.001$. Patients were selected from the outpatient department of the surgical unit of Bakhtawar Amin Medical and Dental College Multan. From April 2015 to April 2016 after diagnosis by high resolution ultrasonography of neck and FNAC. Multinodular goiter was labeled to be present if there were multiple clinically palpable nodules in the thyroid gland. High resolution ultrasound was done to confirm the benign nature of the nodules, showing isoechoic or hyper-echoic areas. FNAC was done in any suspicious area (hypoechoic, irregular margins of a nodule or presence of thick irregular halo) to confirm its benign nature. All those patients having giant and recurrent MNG, thyroid cancer, previously treated with radiotherapy and with coagulation disorder were excluded from the study. Patients having co morbid conditions like, IHD, HTN, CRF and CLD were excluded as well. Informed consent was taken and all procedures were performed by a consultant surgeon (with 5 years post fellowship experience) under general anesthesia. Operative time was calculated from incision to last skin closure using a stop watch. All information was recorded on a specially designed Performa. The effect modifier like age and gender were controlled by stratification. All Collected data was entered in Statistical Package for Social Sciences (SPSS) version 23.1 and was analyzed accordingly. The frequency and percentage were calculated for qualitative variables like gender. Quantitative variables like age and operative time were presented as mean and standard deviation. $\mathrm{T}$ test was applied to compare the mean operative time between two groups. Stratification with respect to age and gender was done. Post stratification t-test was applied on operative time comparison between group $A$ and group $B$. The $p$ value $\leq 0.05$ was taken as significant.

\section{RESULTS}

There were 92 patients in total. Males were 48/92 (52.2\%) while females were 44/92 (47.8\%). Mean age of the patients was $42.75+14.33$ years ranging from a minimum of 13 to a maximum of 60 years. Mean duration of operation was 59.65 +13.85 minutes ranging from a minimum of 37 to a maximum of 87.30 minutes (Table-I). There were 46 patients in treatment group $A$. Males were $21 / 46$ (45.7\%) while females were $25 / 46$ (54.3\%). Mean age of the patients was $44.76+13.87$ ranging from a minimum of 15 to a maximum of 59 years. Mean duration of operation was $47.69+6.51$ ranging from a minimum of 37 to a maximum of 67.5 minutes. In treatment group $B$ there were 46 patients. Males were 27/46 (58.7\%) 
while females were 19/46 (41.3\%). Mean age of the patients was $40.74+14.65$ ranging from a minimum of 13 to a maximum of 60 years. Mean duration of operation was $71.61+7.32$ minutes ranging from a minimum of 56.40 to a maximum of 87.30 (P-value < 0.001) (Table-II). When the effect of gender was noted it was found that among 21 males in treatment group $A$, mean age of the patients was $45.24+14.64$ years and mean duration of operation was $46.60+5.59$ minutes while among 25 females the mean age of the patients was $44.36+13.48$ years and mean duration of operation was $48.60+7.17$ minutes ( $p$-value $=0.31)$. In treatment group $B$ there were 27 males with mean age of $41.07+$ 13.61 years and mean duration of operation was $71.08+6.89$ minutes. There were 19 females in treatment group B with mean age of 40.26 +16.29 years and mean duration of operation 72.35 + 8.02 minutes, P-value was 0.57 (TableIII). When the effect of age was noted it was found that there were 16 patients in treatment group $A$ with age $<40$ years, males were $7 / 16$ (43.8\%) and females were $9 / 16$ (56.2\%). Mean duration of operation was found to be $45.76+7.52$ minutes. In treatment group A there were 30 patients in age group $>40$ years, males were $14 / 30$ (46.7\%) while females were $16 / 30$ (53.3\%) and mean duration of operation was $48.72+5.77$. P-value was found out to be 0.15 . In treatment group B, there were 22 patients in age group $<40$ years, males were $13 / 22$ (59.1\%) while females were $9 / 22(40.9 \%)$ and mean duration of operation was found out to be $69.82+7.49$ minutes. There were 24 patients in treatment group $B$ with age $>40$ years, males were 14/24 (58.3\%) while females were 10/24 (41.7\%) and mean duration of operation was found out to be $73.25+6.91$ $(P$-value $=0.11)($ Table-IV).

\begin{tabular}{|l|c|}
\hline \multicolumn{1}{|c|}{ Characteristics } & $\begin{array}{c}\text { Frequency (Percentages \%) } \\
\mathbf{n = 9 2}\end{array}$ \\
\hline Males & $48 / 92(52.2 \%)$ \\
\hline Females & $44 / 92(47.8 \%)$ \\
\hline Mean age (years) & $42.75+14.33$ \\
\hline $\begin{array}{l}\text { Mean duration of } \\
\text { operation (minutes) }\end{array}$ & $59.65+13.85$ \\
\hline $\begin{array}{l}\text { Table-I. Demographic variables and mean duration of } \\
\text { operation }\end{array}$ \\
\hline
\end{tabular}

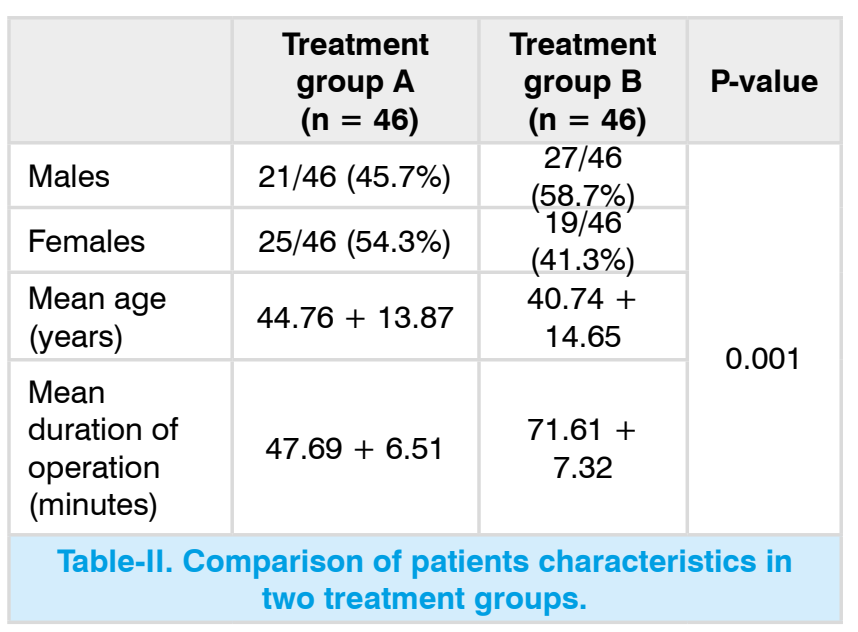

\begin{tabular}{|c|c|c|c|c|}
\hline & & Males & Females & P-value \\
\hline \multirow{2}{*}{$\begin{array}{l}\text { Treatment } \\
\text { group A }\end{array}$} & $\begin{array}{l}\text { Mean age } \\
\text { (years) }\end{array}$ & $\begin{array}{c}45.24 \\
+ \\
14.64\end{array}$ & $\begin{array}{c}44.36 \\
+ \\
13.48\end{array}$ & \multirow{4}{*}{$>0.05$} \\
\hline & $\begin{array}{l}\text { Mean } \\
\text { duration of } \\
\text { operation } \\
\text { (mins) }\end{array}$ & $\begin{array}{r}46.60 \\
+5.59\end{array}$ & $\begin{array}{c}48.60+ \\
7.17\end{array}$ & \\
\hline \multirow{2}{*}{$\begin{array}{l}\text { Treatment } \\
\text { group B }\end{array}$} & $\begin{array}{l}\text { Mean age } \\
\text { (years) }\end{array}$ & $\begin{array}{c}41.07 \\
+ \\
13.61\end{array}$ & $\begin{array}{c}40.26 \\
+ \\
16.29\end{array}$ & \\
\hline & $\begin{array}{l}\text { Mean } \\
\text { duration of } \\
\text { operation } \\
\text { (mins) }\end{array}$ & $\begin{array}{r}71.08 \\
+6.89\end{array}$ & $\begin{array}{c}72.35+ \\
8.02\end{array}$ & \\
\hline
\end{tabular}

Table-III. Comparison of patient characteristics among male and females in treatment in both groups

\begin{tabular}{|c|c|c|c|c|}
\hline & & Age $<40$ & Age $>40$ & P-value \\
\hline \multirow{3}{*}{$\begin{array}{l}\text { Treatment } \\
\text { group A }\end{array}$} & Males & $\begin{array}{c}7 / 16 \\
(43.8 \%)\end{array}$ & $\begin{array}{c}14 / 30 \\
(46.7 \%)\end{array}$ & \multirow{6}{*}{$>0.05$} \\
\hline & Females & $\begin{array}{c}9 / 16 \\
(56.2 \%)\end{array}$ & $\begin{array}{c}16 / 30 \\
(53.3 \%)\end{array}$ & \\
\hline & $\begin{array}{l}\text { Mean } \\
\text { duration of } \\
\text { operation } \\
\text { (mins) }\end{array}$ & $\begin{array}{c}45.76 \\
+ \\
7.52\end{array}$ & $\begin{array}{c}48.72 \\
+ \\
5.77\end{array}$ & \\
\hline \multirow{3}{*}{$\begin{array}{l}\text { Treatment } \\
\text { group B }\end{array}$} & Males & $\begin{array}{c}13 / 22 \\
(59.1 \%)\end{array}$ & $\begin{array}{c}14 / 24 \\
(58.3 \%)\end{array}$ & \\
\hline & Females & $\begin{array}{c}9 / 22 \\
(40.9 \%)\end{array}$ & $\begin{array}{c}10 / 24 \\
(41.7 \%)\end{array}$ & \\
\hline & $\begin{array}{l}\text { Mean } \\
\text { duration of } \\
\text { operation } \\
\text { (mins) }\end{array}$ & $\begin{array}{c}69.82 \\
+ \\
7.49\end{array}$ & $\begin{array}{c}73.25 \\
+ \\
6.91\end{array}$ & \\
\hline \multicolumn{5}{|c|}{$\begin{array}{l}\text { Table-IV. Comparison of patient characteristics among } \\
\text { different age groups in treatment groups A and B }\end{array}$} \\
\hline
\end{tabular}




\section{DISCUSSION}

The thyroid gland is enriched with blood supply via substantial vascular connection, emphasizing the need of meticulous hemostasis in order to obtain a clear surgical field and avoid unintential harm to surrounding vital structures. Despite the fact that thyroidectomy is commonly performed surgical procedure, the best and cost-effective method to achieve homeostasis is still controversial. Therefore, the prevention and control of intra- or postoperative bleeding through various methods is still enjoying the reputation of a topic worth discussing. Electro-coagulation and suture ligation are the conventional methods used for haemostasis in surgery involving thyriod gland.

Out of various methods used for controlling bleeding vessel (e.g., Ligasure precise, lasers, clips, and staples), the development of ultrasonic instruments in the early 1990s has founded a new lineage. ${ }^{15}$ There is no doubt that the harmonic scalpel instruments are both effective and safe in thyroid surgery but the previously used instruments for this purpose are large and inconvenient. The availability of new harmonic scalpel (harmonic focus) since 2008 has made it an alternative method of hemostasis in thyroid surgery compared to a conventional hand-tied ligation. ${ }^{16} \mathrm{~A}$ wide variety of important tasks (e.g., dissection, coagulation, cutting and grasping) can be performed by harmonic focus. The device uses $55.5 \mathrm{kHz}$ of ultrasonic frequency to divide the tissue by disrupting protein hydrogen bonds within the tissue. The harmonic scalpel guarantees the effective heamostasis for blood vessels within the vicinity of $5 \mathrm{~mm}$ of diameter. Lateral thermal injury can be reduced to almost half by using harmonic focus compared to mono-polar systems due to its ability to function at a relatively low temperature. ${ }^{17}$ Meticulous haemostasis is crucial to prevents the intra- and postoperative complications, improve the quality and reduce the postoperative hospital stay. The Kocher's technique of conventional thyroid resections demands a massive amount of instruments mostly for placing ligatures to maintain heamostasis. Various tools like argon plasma coagulation, electrocautery, LigaSure, Ultrasicion and various clips have been introduced to be used in thyroid surgery in recent years. ${ }^{18}$
In our study, 92 patients were included. $52.2 \%$ of them were males while the remaining $47.8 \%$ were females with the mean age of $42.75+14.33$ years reflecting our inclusion criteria. Patients were divided in to two equal groups, Treatment group A received subtotal thyroidectomy with harmonic scalpel while treatment group $B$ received conventional subtotal thyriodectomy. Recorded mean duration of operation time was $47.69+$ 6.51 minutes for group A compared to the mean duration of operation of $71.61+7.32$ minutes. This time difference is statistically significant with a p-value of $<0.001$. Effect of gender and age on the mean duration of operation was not statistically significant among both group $A$ and group B. Our study results are similar to those reported by various studies done by Ferri et al, ${ }^{12}$ Saleh et al, ${ }^{19}$ Nenkov et al, ${ }^{18} \mathrm{He}$ et al, ${ }^{20}$ Sartori et al, ${ }^{21}$ and Siperstein et al. ${ }^{7}$ However, a relatively longer operation times both with harmonic scalpel as well as with conventional ligation method was seen in these studies compared to our study because total thyroidectomy was performed in most of these cases compared to subtotal thyroidectomies performed in our study in order to prevent the development of postoperative hypothyroidism.

The length of surgical incision, extent of resection, use of haemostatic instruments and ligatures, need of draining, intra- and postoperative complications, operative time, length of postoperative hospital stay were explored in a study done by Nenkov et al. ${ }^{18}$ Harmonic scalpel device was used in every patient. Extent of bleeding, use of drainage and operating time was significantly reduced regardless of the extent of resection with no increase incidence of intra- and postoperative complications. A study performed by He et al. ${ }^{20}$ has reported an obvious distinction in the operating time and drainage volume among the Focus (harmonic scalpel) and classic groups of thyriodectomy with the $P$ value of $<$ 0.05 . Nerve injury and permanent hypocalcemia was experienced by none.

In a study conducted by Saleh et al, ${ }^{19} 40$ patients were selected and divided into two groups. Group A underwent thyroidectomy utilizing UAS 
compared to conventional thyroidectomy in Group B patients. Operating time, blood loss, surgeons' satisfaction, dryness of the surgical field and postoperative seroma formation were studied among these groups. Mean operative time and intraoperative blood loss was significantly reduced in group A compared to group B. Moreover, mean total surgeons' satisfaction was significantly high by UAS usage. Similarly, mean operative time, post-operative pain and total drainage fluid volume was significantly reduced by using HS in a study conducted by Ferri et al. ${ }^{14}$ There was no statistically significant difference in mean hospital stay in any group. Transient recurrent laryngeal nerve palsies and postoperative transient hypocalcemia occurred more frequently in group using conventional method of heamostasis.

\section{CONCLUSION}

Subtotal thyroidectomy with harmonic scalpel leads to a significantly reduced mean operative time compared to conventional vessel ligation technique and should be opted routinely for this surgical procedure.

Copyright@ 15 Aug, 2017.

\section{REFERENCES}

1. Agarwal A, Mishra AK, Gupta SK, Arshad F, Agarwal A, Tripathi $\mathrm{M}$, et al. High incidence of tracheomalacia in longstanding goiters: experience from an endemic goiter region. World journal of surgery. 2007;31(4):8327.

2. GreenblattDY, Sippel R, Leverson G, Frydman J, Schaefer $\mathrm{S}$, Chen $\mathrm{H}$. Thyroid resection improves perception of swallowing function in patients with thyroid disease. World journal of surgery. 2009;33(2):255.

3. Maatouk J, Barklow TA, Zakaria W, Al-Abbadi MA. Anaplastic Thyroid Carcinoma Arising in LongStanding Multinodular Goiter Following Radioactive lodine Therapy. Acta cytologica. 2009;53(5):581-3.

4. Mathai $V$, Idikula J, Fenn A, Nair A. Do long $\square$ standing nodular goitres result in malignancies? ANZ Journal of Surgery. 1994;64(3):180-2.

5. Delbridge L. Total thyroidectomy: the evolution of surgical technique. ANZ journal of surgery. 2003;73(9):761-8.

6. Kilic M, Keskek M, Ertan T, Yoldas O, Bilgin A, Koc
M. A prospective randomized trial comparing the harmonic scalpel with conventional knot tying in thyroidectomy. Advances in therapy. 2007;24(3):632-8.

7. Siperstein AE, Berber E, Morkoyun E. The use of the harmonic scalpel vs conventional knot tying for vessel ligation in thyroid surgery. Archives of Surgery. 2002;137(2):137-42.

8. Vanella S, Crocco A, Traini E, Lombardi CP, Raffaelli M. Hemostatic Devices. Minimally Invasive Therapies for Endocrine Neck Diseases: Springer; 2016. p. 23748.

9. Yener O, Demir M, Yılmaz A, Yıgıtbaşı R, Atak T. Harmonic scalpel compared to conventional hemostasis in thyroid surgery. Indian Journal of Surgery. 2014;76(1):66-9.

10. Pons $Y$, Gauthier J, Ukkola-Pons E, Clément $P$, Roguet $\mathrm{E}$, Poncet J-L, et al. Comparison of LigaSure vessel sealing system, harmonic scalpel, and conventional hemostasis in total thyroidectomy. OtolaryngologyHead and Neck Surgery. 2009;141(4):496-501.

11. Revelli L, Damiani G, Bianchi CBNA, Vanella S, Ricciardi $W$, Raffaelli $M$, et al. Complications in thyroid surgery. Harmonic Scalpel, Harmonic Focus versus Conventional Hemostasis: a meta-analysis. International Journal of Surgery. 2016;28:S22-S32.

12. Ferri $E$, Armato $E$, Spinato G, Spinato R. Focus harmonic scalpel compared to conventional haemostasis in open total thyroidectomy: a prospective randomized trial. International journal of otolaryngology. 2011;2011.

13. Ecker T, Carvalho AL, Choe J-H, Walosek G, Preuss $\mathrm{KJ}$. Hemostasis in thyroid surgery: harmonic scalpel versus other techniques-a metaanalysis. Otolaryngology-Head and Neck Surgery. 2010;143(1):17-25.

14. Ferri E, Armato E, Spinato G, Lunghi M, Tirelli G, Spinato R. Harmonic scalpel versus conventional haemostasis in neck dissection: a prospective randomized study. International journal of surgical oncology. 2013;2013.

15. Romano F, Garancini M, Uggeri F, Gianotti L, Nespoli L, Nespoli $A$, et al. The aim of technology during liver resection-a strategy to minimize blood loss during liver surgery. Hepatic surgery: InTech; 2013.

16. Butskiy O, Wiseman SM. Electrothermal bipolar vessel sealing system (LigaSure ${ }^{\mathrm{Tm}}$ ) for hemostasis during thyroid surgery: a comprehensive review. Expert review of medical devices. 2013;10(3):389-410.

17. Medina-Meza IG, Barnaba C, Barbosa-Cánovas GV. Effects of high pressure processing on lipid 
oxidation: A review. Innovative Food Science \& Emerging Technologies. 2014;22:1-10.

18. Nenkov R, Cvetkov $N$. The harmonic scalpel application in thyroid surgery. Journal of IMAB-Annual Proceeding Scientific Papers. 2013;19(1):408-11.

19. Saleh M, Sharari N, Morad A. Impact of Ultrasonically Activated Scalpel on Thyroid Surgery. J Def Manag S. 2013;3:007.
20. He Q, Zhuang D, Zheng L, Zhou P, Chai J, Lv Z. Harmonic focus in total thyroidectomy plus level III-IV and VI dissection: a prospective randomized study. World journal of surgical oncology. 2011;9(1):141.

21. Sartori PV, De Fina S, Colombo G, Pugliese F, Romano $F$, Cesana $G$, et al. Ligasure versus Ultracision ${ }^{\circledR}$ in thyroid surgery: a prospective randomized study. Langenbeck's Archives of Surgery. 2008;393(5):655-8.

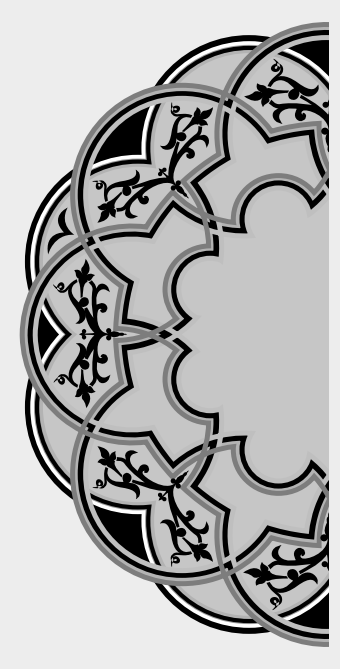

\title{
"Tell me and I forget. Teach me and I remember. Involve me and I learn."
}

\author{
Benjamin Franklin
}

\section{AUTHORSHIP AND CONTRIBUTION DECLARATION}

\begin{tabular}{|c|l|l|}
\hline Sr. \# & \multicolumn{1}{|c|}{ Author-s Full Name } & \multicolumn{1}{|c|}{ Contribution to the paper } \\
\hline 1 & Shabbir Ahmed & Conceived idea, Study design \\
\hline 2 & Ishtiaq Ahmad & Data collection \\
\hline 3 & Asad Riaz & Manuscript writting \\
\hline 4 & Aamir Furqan & Data analysis, Proof reading \\
\hline
\end{tabular}

